\title{
COVID-19: DO MEDICAL STUDENTS KNOW, BOTHER ABOUT, AND PRACTISE PREVENTIVE MEASURES IN MALAYSIA?
}

\author{
Md Mizanur Rahman ${ }^{*}$, Mohaamad Shaah ${ }^{1}$, Yuggesh Kumar ${ }^{1}$, Sumeetha Marimuthu ${ }^{1}$, Mithrra Sundaram $^{1}$, \\ Shaundari Muniandy ${ }^{1}$, Mahanagaraani Yogeswaran ${ }^{1}$ and Shamilaa Bala Krishnan Muthiah ${ }^{1}$
}

${ }^{1}$ Faculty of Medicine and Health Sciences, Universiti Malaysia Sarawak, Malaysia

*Corresponding author: Md Mizanur Rahman

Email: rmmizanur@unimas.my

\begin{abstract}
Since December 2019, a novel coronavirus disease (COVID-19) creates a global threat. Medical students are more susceptible to be infected by the virus. This study aimed to assess COVID-19 related knowledge, attitude towards COVID-19, and preventive behaviours against COVID-19 among medical students within the first month of the onset of the outbreak in Malaysia. We collect data from medical students using an online Google survey form. Out of 696 students, 467 responded to the questionnaire. The analysis revealed that the mean percentage of knowledge was (85.04), attitude (84.12), and preventive practice (77.75) respectively. Hierarchical multiple linear regression analysis revealed that living with family $(p<0.01)$ and knowledge of COVID-19 $(p<0.001)$ appeared to be important predictors of attitude toward COVID-19. However, gender $(p<0.001)$, living status $(p<0.001)$, frequency of travel during movement control order $(p<0.01)$, attitude towards COVID-19 $(p<0.001)$ have appeared significant predictors for preventive practice against COVID-19. But knowledge of COVID-19 had no impact on preventive practice against COVID-19 ( $p>0.05)$. We found a high level of COVID-19 related knowledge, attitude, and preventive practice against COVID-19 among medical students. A sustained knowledge, attitude, and preventive behavioural strategy could play an ingredient in upholding the student's learning and practice against any disease like COVID-19.
\end{abstract}

Keywords: knowledge, attitude, practice, COVID-19, Sarawak,

\section{INTRODUCTION}

On 31st December 2019, 27 cases of pneumonia of unknown aetiology were identified in Wuhan City, Hubei province in China ${ }^{1}$. Most of them had similar clinical presentations such as dry cough, dyspnoea, fever, and bilateral lung infiltrates on imaging. It was diagnosed as a coronavirus disease 2. The disease was later named COVID-19 by the World Health Organization ${ }^{3}$. The majority of COVID-19 patients manifest similar clinical symptoms as SARS-CoV, which are commonly fever, dry cough, dyspnoea, chest pain, fatigue, and myalgia. Other symptoms, such as abdominal pain, diarrhoea, nausea, headache, and vomiting, are less common among these patients ${ }^{4}$. People older than 60 years of age, and those with comorbidities are vulnerable to a more severe form of the disease compared to other age groups 1 . Most members of the coronavirus family are zoonotic viruses that are transmitted to humans via contact with infected animals. Although bats and snakes are the natural reservoirs of a wide range of coronaviruses, there is no evidence so far that the COVID-19 originated and was transmitted from the seafood market ${ }^{5-7}$. Mode of the spread of this SARS-CoV-2 virus is between persons via respiratory droplets from coughs and sneezes ${ }^{8}$. Several preventive methods have been carried out by governments, but people's responses toward rules and regulations vary, and this has resulted in a difference in compliance ${ }^{9}$.
The Government of Malaysia implemented the Movement Control Order (MCO) on $18^{\text {th }}$ March 2020 as a preventive measure to battle against the COVID-19 pandemic in the country ${ }^{10}$. This approach aims to slow epidemic growth, reducing case numbers to low levels by the social distancing of the entire population, closing schools and universities, and halting all nonessential economic activities ${ }^{8}$. Regular handwashing and home quarantine have been the main preventive methods to prevent the widespread transmission of this disease ${ }^{11,12}$. Still, the general peoples are not aware of this; hence the number of cases reflects the level of compliance. The people's response to these regulations, as reflected in their level of compliance and perception of the seriousness of the problem, is the determining factor in health authorities' struggle in containing the pandemic.

Considering the global pandemic of COVID-19, many educational institutions worldwide have suspended physical classes to maintain social distancing. However, the general awareness of medical students regarding the critical aspects of COVID-19, their attitude towards COVID-19 and preventive practice against it are essential to combat the rapid transmission of the disease, and prevention of COVID-19. Medical students may have close contact with infected people. Lack of proper knowledge and preventive measure can 
make them over- or underestimate the situation. Since COVID-19 is currently spreading in Malaysia and also all over the world, now is an opportune time to assess medical student's awareness, attitude, and preventive behaviour with respect to the infection. There is a limited number of studies available on the subject, especially in Malaysia, so this survey aims to assess these parameters among UNIMAS medical students.

\section{METHODS}

\section{Study setting}

This cross-sectional study was designed to collect information on awareness, attitude, and preventive practice of COVID-19 among UNIMAS medical students. The inclusion criteria were students aged 18 years and above, irrespective of gender and nationality, who gave consent, can understand English, and is currently an undergraduate medical student in the Faculty of Medicine and Health Sciences (FMHS) in UNIMAS. The total number of medical students from year 1 to year 5 was 696. All the medical students in the Faculty of Medicine and Health Sciences were considered as the study sample, and they were all invited to participate in this study.

\section{Data collection instruments and procedure}

Data was collected using a non-probability method whereby we developed a validated set questionnaire in a Google data collection form in English and Malay language, which was distributed by group email. This method was used due to the current Malaysian Government implementation of restricted movement order (RMO). The questionnaire was composed of pre-designed structured questionnaires, i.e., self-administered questionnaires. The instrument had four parts which were: Part 1: Demographics, personal and behavioural characteristics of the students; Part 2: knowledge of COVID-19; Part 3: attitude towards COVID-19; and Part 4: the preventive practice against COVID-19 among UNIMAS medical students.

\section{Measurements \\ Knowledge of COVID-19 was assessed using 18 items of the question 2,13,14. These questions were answered on a true/false basis with an additional "I don't know" option. A correct answer was assigned 1 point, and an incorrect/unknown answer was assigned 0 points. A summative score was calculated first and then transformed into a percentage for easy comparison with other variables.}

Attitude towards COVID-19 was assessed by 14 item questions with Likert's scale. The 5- point rating scale, ranging from one (1) "strongly disagree" to five (5) "strongly agree" was used. A maximum score of 5 was given for "strongly agree" except for Section 3, question 3, which had reverse scoring. A composite mean score of attitudes was calculated first and then transformed into a percentage.

Preventive practice against COVID-19 was assessed by 13 item questions with Likert's scale. The items in the question include social distancing, wearing a mask, hand sanitisation, covering mouth and nose when sneezing with tissue followed by its disposal, taking a bath after returning home from outside, drinking traditional drinks and face touching habits. These questions were answered on a range of never (score zero) to always (score 4). A composite mean score of preventive practice was calculated first and then transformed into a percentage. Demographic, personal, and behavioural characteristics include age, gender, years of study, family size, and place of residence. The others were social media uses, physical exercise, frequency of movement during MCO, social gathering and contact with COVID-19 patients.

\section{Data entry and analysis}

All the responses were automatically saved in the Microsoft Excel file. The Excel data were imported to IBM Statistical Package for Social Sciences (SPSS) version 22.0 for analysis 15 . A oneway analysis of variance (ANOVA) for polytomous and an independent sample t-test for dichotomous independent variables was done to determine the factors affecting the knowledge of COVID-19, attitude toward COVID-19 and preventive practice against COVID-19 (Table 2). The dependent or test variables were knowledge, attitude, and preventive practice as a continuous dependent variable. Post hoc tests were done to confirm where the differences occurred between groups if a variable showed an overall statistically significant difference in group means. If the data met the assumption of homogeneity of variances, we used Tukey's honestly significant difference (HSD) post hoc test, otherwise, Games Howell post hoc test 16,17 .

Finally, a hierarchical multiple linear regression analysis was done to determine the factors associated with the attitude towards COVID-19 and preventive practice against COVID-19 and the selected variable. The independent variables were the age of the students, living status and frequency of movement during MCO. The categorical gender variable was dummy coded into females scored as ' 1 ' and male as ' 0 ' and the living status living with family dummy coded as ' 1 ' and not living with family scored ' 0 '. The age of the students and the frequency of movement were treated as continuous variables. A standardised latent variable score was calculated from the item of the statement in knowledge, attitude, and preventive practice against COVID19 using factor analysis ${ }^{18}$. A total of twenty-five data were removed due to outliers. In the analytic model, age, gender, frequency of movement during $\mathrm{MCO}$, and living status were entered in the 
first stage, while the latent knowledge and attitude scores were entered in the second stage. In the first and second models, the adjusted Rsquare was examined for model improvement 21 and the percentage of variability explained by the explanatory variables. Before interpreting the output, the ANOVA table (F-statistics) was examined for contributing significant predictors and to test the null hypothesis of the beta coefficient equal to zero. This indicated whether at least one independent variable reliably predicts the dependent variable. The part correlation of each output was also examined for unique contribution (variance) of the explanatory variable in the fitted model that explains the dependent variable. A p-value of less than 0.05 was considered statistically significant.

\section{Ethical issues}

Concerning the possible ethical issues related to this research, the participation of students in this research was voluntary. The identity and personal information of the students were kept confidential to ensure the personal information of the students was not disclosed. The ethics approval has been obtained from the ethics committee of the Faculty of Medicine and Health Sciences.

\section{RESULTS}

\section{Characteristics of the students}

Table 1 illustrates the characteristics of medical students. The mean age (SD) of the students was 21.8 (1.4) years with a minimum age of 19 and a maximum of 25 years. Three-fourths $(73.4 \%)$ of the students were female, and the rest were male $(26.6 \%)$ with male and female ratio $1: 2.76$. Fiftysix percent of the students did not move during the MCO period. Very few students had a history of social gathering and contact with infected COVID-19.

\section{Knowledge, attitude, and practices against COVID-19}

Figure 1 depicts the mean percentage of knowledge of COVID-19, attitude towards COVID19, and preventive practices against COVID-19. The mean percentage of knowledge of COVID-19 was 85.04 with a standard deviation of 7.6 . The minimum score was 44.4 and the maximum score 100.0. The mean percentage of attitude (SD) score was $84.12(7.3)$ with a minimum of 37.29 and the maximum score 100.0. The preventive practice against COVID-19 was less than knowledge and attitude with a mean (SD) was 77.75(11.5) with a minimum of 44.0 and maximum 100.0

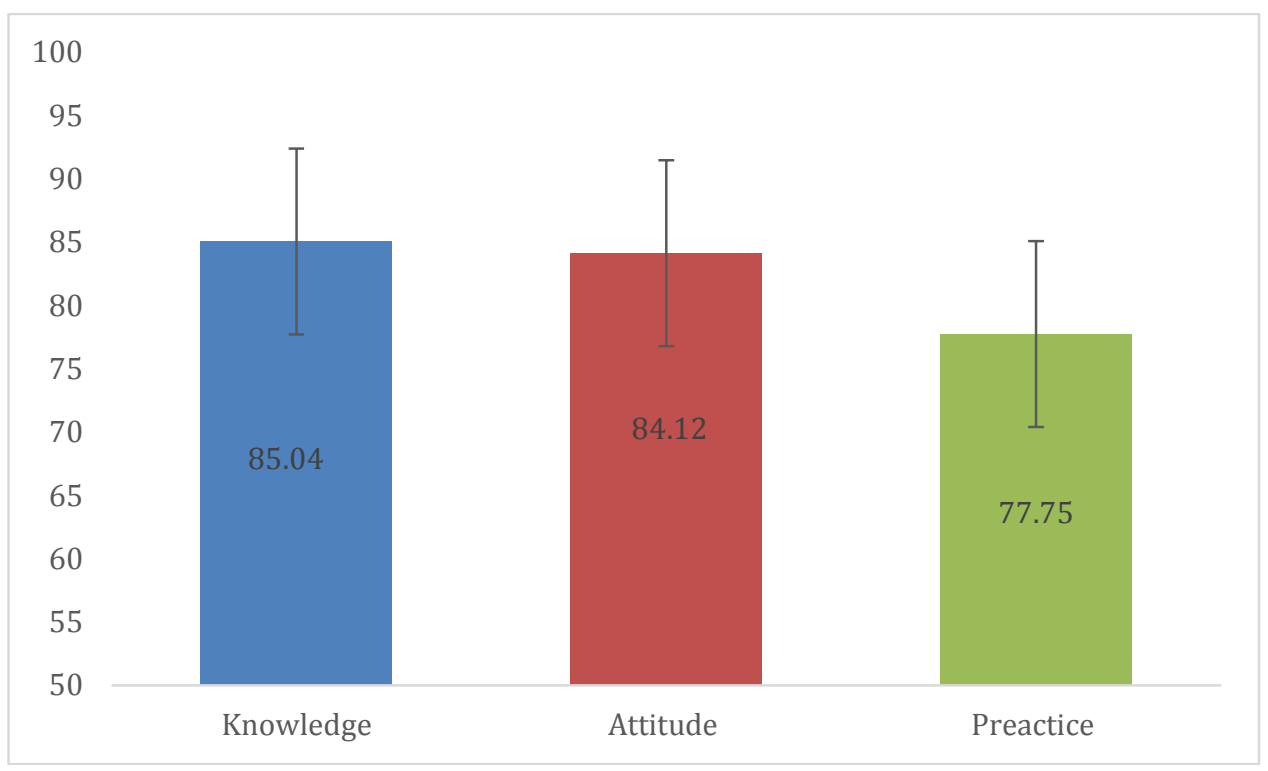

Figure 1 Mean percentage with error bar $(95 \% \mathrm{Cl})$ of knowledge, attitude, and preventive practice against Covid-19

Factors affecting knowledge, attitude, and preventive practice against COVID-19:

Bivariate analysis

The analysis revealed that there was a mean difference in knowledge score among the year of study $(p<0.001)$. The posthoc test indicated that the year-1 (mean=15.70, SD=1.3) students had significantly better knowledge than year-2 (mean=15.05, SD=1.4), and also Year-3 (Mean $15.05, S D=1.4)(p<0.05)$, but no significant mean difference was found between year-4 and yea-5 students $(p>0.05)$. No other variables had a statistically significant mean difference $(p>0.05)$. In terms of attitude towards COVID-19, the students living with family and relatives had a better attitude (mean $=4.25, \mathrm{SD}=0.3$ ) towards COVID-19 than the students living in a university hostel or off-campus during MCO period (mean=4.16, SD=0.4) and the mean difference was statistically significant $(p=0.013)$. In terms of preventive practice against COVID-19, age, year of study, gender, living status, and frequency of 
movement during the MCO period appeared to be significantly associated $(p<0.001)$. Post hoc analysis revealed that age at 23 and above had better preventive practice (mean $=3.22, \mathrm{SD}=0.4$ ) than the other age group. The year-4 students had a significant mean difference of preventive practice with year-1 and Year-2 students $(p<0.001)$, but no statistically significant difference was found year- 3 and Year-5 students $(p>0.05)$. The female students had better preventive practice (mean=3.19) than male students (mean=2.89). Similarly, those who were living with family had better preventive practice (mean=3.25) than the living with university campus or off-campus (mean=2.97). The mean score of preventive practice was high among the students who travel one time or more $(p<0.05)$ without movement (mean = 3.01) except movement 4-times and above ( $>>0.05)$ (Table 2$)$.

\section{Factors affecting attitude and preventive practice against COVID-19: A hierarchical multiple linear regression analysis}

Table 3 shows the analysis of multiple linear regression. In terms of attitude towards COVID19 , in the initial model, living with family appeared to be important predictors $(B=0.111$, $p<0.5)$. After entering the knowledge score in the second model, it slightly decreases $(B=0.106$, $\mathrm{p}<0.05)$. However, the knowledge score appeared to be a significant predictor of attitude $(B=0.186$, $\mathrm{p}<0.001)$. Analysis of preventive practice against COVID-19 showed that gender, living status, and frequency of travel during MCO appeared to be significant predictors, but age was not significant. However, with the inclusion of knowledge and attitude scores, the model significantly improved. The analysis found that gender $(B=0.215, p<0.001)$, living status $\quad(B=0.265$, $p<0.001)$, frequency of movement during $M C O$ $(B=0.128, p<0.01)$ and attitude towards COVID-19 $(B=0.268, p<0.001)$ appeared to be important predictors of preventive practice against COVID19. However, knowledge of COVID-19 had no impact on preventive practice against COVID-19 $(p>0.05)$. Analysis of the semi-partial coefficient indicated that the highest contributing factor was the attitude towards COVID-19 (26.1\%) followed by living with family $(25.6 \%)$, gender $(21.3 \%)$, and lowest in movement during MCO period (12.3\%).

\section{DISCUSSION}

Our analysis found substantial knowledge, attitude, and preventive practice against COVID19 among the medical students with a mean percentage of knowledge (85.04\%) and attitude (84.12\%). The findings are consistent with Taghrir et al. ${ }^{22}$, Erfani et al. ${ }^{23}$ in Iran and Zhong et al. ${ }^{2}$ in China, and even though the preventive practice was good enough, it was a little bit lower than that found by Taghrir et al. ${ }^{22}$. The overwhelming knowledge, attitude, and preventive practice might be due to the lethal and fast-spreading outbreak, shaping the mindset of the medical students. These young students had gravitated towards the medical profession, and they have to learn grievous diseases like COVID-19. Another explanation might be that knowledge, attitude, and practice for a particular infectious illness could be influenced by various factors such as the gravity of the disease, the severity of its spread and the fatality rate. Ever since the announcement of COVID-19 as a pandemic by the WHO ${ }^{3}$, the knowledge, attitude and practices toward COVID-19 have been growing day by day.

We found that overall knowledge about the symptoms, causes, unavailability of vaccine or specific antiviral treatment against COVID-19 was good, where more than $90 \%$ of students know about it. The findings were consistent with the previous studies ${ }^{2,4,24}$. This is proven by the fact that almost all students were aware of the common symptoms of COVID-19. More than $90 \%$ of students were also aware of the importance of isolation after travelling or exposed to COVID-19 patients, self-hygiene, and the importance of non-medical measures. This could be an essential finding explained on various factors such as the seriousness of the disease and ways to prevent from getting infected as circulated by different media and health authorities especially after being declared a pandemic by the WHO ${ }^{25}$ and the effectiveness of different awareness campaigns conducted within the country ${ }^{26}$. Bivariate analysis revealed that knowledge of COVID-19 is found to be high among Year 1 students. The explanation might be due to media exposure and the latest information from the University. However, the year-5 students had a higher level of awareness compared to Year-2, Year-3, and Year-4, but it was not statistically significant.

In our analysis, we found that the attitude towards COVID-19 was significantly correlated with knowledge of COVID-19 $(p<0.001)$. This finding follows knowledge-attitude-behaviour model ${ }^{27}$. Knowledge is essential for effective changes in behaviour ${ }^{28}$, and individuals can obtain knowledge and skills through learning. That means the higher the awareness of any phenomenon, the higher the concern (Attitudes) about the phenomenon 29,30 . Liu et al. ${ }^{27}$ argued that peoples and families need to actively receive knowledge, which can lead to a gradual development of healthy beliefs and attitudes that are reinforced with the adoption of healthy behaviours. This argument supports our finding; the students who are living with their families during the MCO period, i.e., during pandemic had an optimistic attitude towards COVID-19. 
Table 1: Characteristics of the students

\begin{tabular}{|c|c|c|c|}
\hline Characteristics & Count & $\%$ & Statistics \\
\hline \multicolumn{4}{|l|}{ Age in years } \\
\hline $19-20$ & 99 & 21.2 & Mean $(S D)=21.8(1.4)$ \\
\hline $21-22$ & 211 & 45.2 & Median $=22.0$ \\
\hline$\geq 23$ & 157 & 33.6 & $\operatorname{Min}=19, \operatorname{Max}=25$ \\
\hline \multicolumn{4}{|l|}{ Year of study } \\
\hline Year 1 & 106 & 22.7 & \\
\hline Year 2 & 117 & 25.1 & \\
\hline Year 3 & 105 & 22.5 & \\
\hline Year 4 & 99 & 21.2 & \\
\hline Year 5 & 40 & 8.6 & \\
\hline \multicolumn{4}{|l|}{ Gender } \\
\hline Male & 124 & 26.6 & \\
\hline Female & 343 & 73.4 & \\
\hline \multicolumn{4}{|l|}{ Living status } \\
\hline Living with family & 217 & 46.5 & \\
\hline Living with relatives & 13 & 2.8 & \\
\hline Outside campus & 48 & 10.3 & \\
\hline University college & 189 & 40.5 & \\
\hline \multicolumn{4}{|l|}{ Family size } \\
\hline $1-4$ & 114 & 24.4 & Mean $(S D)=5.6(1.6)$ \\
\hline $5-6$ & 242 & 51.8 & Median $=5.5$ \\
\hline$\geq 7$ & 111 & 23.8 & \\
\hline \multicolumn{4}{|l|}{ Exercise during $M C O$} \\
\hline No exercise & 110 & 23.6 & \\
\hline Not frequent & 263 & 56.3 & \\
\hline Frequent & 94 & 20.1 & \\
\hline \multicolumn{4}{|l|}{ Social media uses (hours) } \\
\hline $1-5$ & 122 & 26.1 & Mean $(S D)=9.8(6.0)$ \\
\hline $6-10$ & 173 & 37.0 & Median $=8.0$ \\
\hline $11-15$ & 99 & 21.2 & \\
\hline$\geq 16$ & 73 & 15.6 & \\
\hline \multicolumn{4}{|c|}{ Frequency of travel during $\mathrm{MCO}$} \\
\hline 0 & 260 & 55.7 & Mean $(S D)=1.2(1.7)$ \\
\hline 1 & 58 & 12.4 & Median $=0.0$ \\
\hline 2 & 63 & 13.5 & $\operatorname{Min}=0, \operatorname{Max}=6$ \\
\hline 3 & 32 & 6.9 & \\
\hline$\geq 4$ & 54 & 11.6 & \\
\hline \multicolumn{4}{|c|}{ Social gathering during $M C O$} \\
\hline No & 463 & 99.1 & \\
\hline Yes & 4 & 0.9 & \\
\hline \multicolumn{4}{|l|}{ Contact with COVID-19 } \\
\hline No & 459 & 98.3 & \\
\hline Yes & 8 & 1.7 & \\
\hline
\end{tabular}

The family members were sources of encouragement and played pivotal roles to participate in healthy activities and helped to change behaviour. The high number of students who agreed that the COVID-19 outbreak could be successfully controlled due to the strong government implementation of Movement Control Order (MCO), also to home quarantine, social distancing and prevention of mass gathering. This correlates to a KAP study in Malaysia, where it attributed that a large majority of peoples held positive attitudes towards overcoming COVID-19
30. The fact that very few students had a negative attitude towards Movement Control Order (MCO) even though it was a problem for them shows their resoluteness to follow through the order the government has implemented to break through this pandemic. This might be due to the fact that people assume and expect certain outcomes from life, but life is not meant to be controlled by them. They have all the possibilities to expand and enrich their life. Self-indulgence might be the cause of having a negative attitude about life ${ }^{31}$. 
Table 2: Factors affecting knowledge, attitude, and preventive practice against COVID-19: Bivariate analysis

\begin{tabular}{|c|c|c|c|c|}
\hline \multirow[t]{2}{*}{ Variables } & \multicolumn{4}{|c|}{ Mean (SD) } \\
\hline & $\mathrm{n}$ & Knowledge & Attitude & Practice \\
\hline \multicolumn{5}{|l|}{ Age in years } \\
\hline $19-20$ & 99 & $15.55(1.3)$ & $4.19(0.4)$ & $3.03(0.5)$ \\
\hline $21-22$ & 211 & $15.16(1.4)$ & $4.19(0.4)$ & $3.06(0.5)$ \\
\hline$\geq 23$ & 157 & $15.36(1.4)$ & $4.24(0.3)$ & $3.22(0.4)$ \\
\hline sp-value & & 0.053 & 0.474 & 0.001 \\
\hline \multicolumn{5}{|l|}{ Year of study } \\
\hline Year 1 & 106 & $15.70(1.3)$ & $4.18(0.4)$ & $3.04(0.5)$ \\
\hline Year 2 & 117 & $15.05(1.4)$ & $4.15(0.3)$ & $3.01(0.5)$ \\
\hline Year 3 & 105 & $15.05(1.3)$ & $4.24(0.4)$ & $3.13(0.5)$ \\
\hline Year 4 & 99 & $15.43(1.4)$ & $4.26(0.3)$ & $3.25(0.4)$ \\
\hline Year 5 & 40 & $15.40(1.4)$ & $4.18(0.4)$ & $3.19(0.4)$ \\
\hline sp-value & & 0.001 & 0.171 & 0.001 \\
\hline \multicolumn{5}{|l|}{ Gender } \\
\hline Male & 124 & $15.31(1.5)$ & $4.16(0.5)$ & $2.89(0.5)$ \\
\hline Female & 343 & $15.31(1.3)$ & $4.22(0.3)$ & $3.19(0.4)$ \\
\hline Ep-value & & 0.986 & 0.074 & 0.001 \\
\hline \multicolumn{5}{|l|}{ Residence } \\
\hline Living with family & 230 & $15.28(1.3)$ & $4.25(0.3)$ & $3.25(0.4)$ \\
\hline Outside family & 237 & $15.33(1.4)$ & $4.16(0.4)$ & $2.97(0.5)$ \\
\hline$p$-value & & 0.689 & 0.013 & 0.001 \\
\hline \multicolumn{5}{|l|}{ Family size } \\
\hline $1-4$ & 114 & $15.34(1.3)$ & $4.22(0.3)$ & $3.16(0.4)$ \\
\hline $5-6$ & 242 & $15.31(1.4)$ & $4.20(0.4)$ & $3.10(0.5)$ \\
\hline$\geq 7$ & 111 & $15.27(1.4)$ & $4.20(0.3)$ & $3.09(0.4)$ \\
\hline sp-value & & 0.982 & 0.859 & 0.441 \\
\hline \multicolumn{5}{|l|}{ Exercise during $M C O$} \\
\hline No exercise & 110 & $15.21(1.3)$ & $4.24(0.3)$ & $3.05(0.5)$ \\
\hline Not frequent & 263 & $15.38(1.3)$ & $4.19(0.4)$ & $3.12(0.4)$ \\
\hline Frequent & 94 & $15.22(1.6)$ & $4.23(0.4)$ & $3.16(0.5)$ \\
\hline sp-value & & 0.434 & 0.369 & 0.251 \\
\hline \multicolumn{5}{|c|}{ Social media uses (hrs) } \\
\hline $1-5$ & 122 & $15.36(1.4)$ & $4.21(0.4)$ & $3.10(0.5)$ \\
\hline $6-10$ & 173 & $15.30(1.4)$ & $4.20(0.4)$ & $3.07(0.5)$ \\
\hline $11-15$ & 99 & $15.18(1.2)$ & $4.21(0.4)$ & $3.18(0.4)$ \\
\hline$\geq 16$ & 73 & $15.41(1.4)$ & $4.22(0.4)$ & $3.11(0.4)$ \\
\hline$\S P$-value & & 0.696 & 0.963 & 0.300 \\
\hline \multicolumn{5}{|c|}{ Movement during MCO } \\
\hline 0 & 260 & $15.39(1.4)$ & $4.19(0.4)$ & $3.01(0.5)$ \\
\hline 1 & 58 & $14.90(1.3)$ & $4.25(0.3)$ & $3.21(0.4)$ \\
\hline 2 & 63 & $15.22(1.4)$ & $4.26(0.4)$ & $3.32(0.4)$ \\
\hline 3 & 32 & $15.50(1.2)$ & $4.21(0.3)$ & $3.28(0.4)$ \\
\hline$\geq 4$ & 54 & $15.33(1.4)$ & $4.19(0.3)$ & $3.13(0.6)$ \\
\hline sp-value & & 0.128 & 0.542 & 0.001 \\
\hline \multicolumn{5}{|l|}{ Social gathering } \\
\hline No & 463 & $15.32(1.4)$ & $4.21(0.4)$ & $3.11(0.5)$ \\
\hline Yes & 4 & $14.00(0.8)$ & $4.11(0.5)$ & $2.83(0.9)$ \\
\hline$p$-value & & 0.054 & 0.589 & 0.216 \\
\hline \multicolumn{5}{|c|}{ Contact with Covid-19 } \\
\hline No & 459 & $15.30(1.4)$ & $4.21(0.4)$ & $3.11(0.5)$ \\
\hline Yes & 8 & $15.75(1.6)$ & $4.22(0.2)$ & $3.17(0.3)$ \\
\hline$£ £ p$-value & & 0.357 & 0.894 & 0.697 \\
\hline
\end{tabular}

sp-value reached from one-way analysis of variance $£ p$-value reached from independent sample t-test ${ }^{*} p<0.005,{ }^{* *} p<0.01,{ }^{* * *} p<0.001$ 
Table 3: Factors affecting attitude and preventive practice against COVID-19: Hierarchical multiple regression analysis

\begin{tabular}{|c|c|c|c|c|c|c|c|c|c|c|c|c|}
\hline \multirow{2}{*}{ Parameters } & \multicolumn{6}{|c|}{ Attitude toward Covid-19 } & \multicolumn{6}{|c|}{ Preventive Practice against Covid-19 } \\
\hline & B & SE & Beta & $\overline{\mathrm{LL}}$ & UL & Part & B & SE & Beta & $\overline{\mathrm{LL}}$ & UL & Part \\
\hline (Constant) & $-.39^{* *}$ & .651 & & -1.673 & .887 & & $-1.70^{* *}$ & .651 & & -2.983 & -.424 & \\
\hline Age in years & .015 & .030 & .025 & -.043 & .074 & .024 & .048 & .030 & .072 & -.011 & .106 & .070 \\
\hline Gender (female) & .077 & .093 & .040 & -.106 & .261 & .039 & .481 & .093 & $.226^{* * *}$ & .298 & .664 & .224 \\
\hline 1 Living status (family) & .187 & .082 & $.111^{*}$ & .025 & .348 & .108 & .543 & .082 & $.295^{* * *}$ & .382 & .704 & .287 \\
\hline $\begin{array}{l}\text { Frequency of travel during } \\
\text { MCO }\end{array}$ & -.033 & .030 & -.053 & -.092 & .027 & -.051 & .077 & .030 & $.114^{* * *}$ & .018 & .136 & .110 \\
\hline \multirow{7}{*}{$\begin{array}{l}\text { (Co } \\
\text { Age } \\
\text { Ger }\end{array}$} & -.418 & .640 & & -.043 & .074 & & -1.589 & .624 & & -2.815 & -.363 & \\
\hline & .016 & .029 & .026 & -.097 & .020 & .025 & .043 & .029 & .066 & -.013 & .100 & .063 \\
\hline & .075 & .092 & .039 & -1.676 & .841 & .038 & .458 & .089 & $.215^{* * *}$ & .283 & .634 & .213 \\
\hline & .178 & .081 & $.106^{*}$ & -.105 & .256 & .103 & .488 & .079 & $.265^{* * *}$ & .333 & .643 & .256 \\
\hline & -.038 & .030 & -.062 & .019 & .337 & -.060 & .086 & .029 & $.128^{* *}$ & .029 & .143 & .123 \\
\hline & .329 & .083 & $.186^{* * *}$ & -.042 & .073 & .186 & .010 & .082 & .005 & -.151 & .171 & .005 \\
\hline & & & $\mathrm{NI}$ & & & & .293 & .047 & $.268^{* * *}$ & .202 & .385 & .261 \\
\hline $\begin{array}{l}\text { Adj } R^{2} \text { Model } 1 \text { and } 2 \\
F(d f) \text { ratio }\end{array}$ & \multicolumn{6}{|c|}{$\begin{array}{l}0.007 \text { and } 0.040^{* * *} \\
441) \text { and } 4.633(5 \text {, }\end{array}$} & \multicolumn{6}{|c|}{$172^{* * *}$ and $0.240^{* * *}$} \\
\hline
\end{tabular}
${ }^{*} p<0.05,{ }^{* *} p<0.01,{ }^{* * *} p<0.001, N I=$ Not included

We found that most of the medical students, which is about $77.8 \%$, have taken appropriate preventive measures against COVID-19. A similar finding was reported by Zhong et al. ${ }^{2}$ among the Chinese residents. The preventive practice was found to be the highest among students who are 23 years old and above even though their knowledge regarding COVID-19 was low compared to students who were 19 and 20 years old because the older students take this pandemic outbreak as a serious issue. They know the importance of taking preventive measures against COVID-19. Year 4 students practice more preventive measures as they have a higher level of attitude towards COVID 19 compared with other students. Apart from that, female students have a higher mean for preventive practice, and this is because female students are more hygienic and more responsible than the male counterpart. Moreover, students who are living with their families take more preventive measures to compare to those who are living are outside; this is due to enforcement by the family members. Another explanation might be that each family's unique qualities and dynamics, values and norms influence the changed behaviour. Mostly the students travel only twice during this MCO period as they are aware of the importance of restriction of movement.

The preventive practice was found to be the highest among students who are 23 years old and above even though their knowledge regarding COVID-19 was low compared to students who are 19 and 20 years old because older students take this pandemic outbreak as a serious issue. Apart from that, female students have a higher mean for preventive practice. This is because female students are more hygienic and have a better attitude towards COVID-19 compare to male students, supported by a research conducted by Erfani et al. ${ }^{23}$ where knowledge, attitude and practice towards COVID-19 score was significantly higher among females. This might be a fact that the females are more practising healthy lifestyles, whereas the males are prone to risk-taking behaviour ${ }^{32-34}$. The females are less attracted to risky behaviours because they judge the potential adverse, negative outcomes, and find the positive emotions associated with risk-taking behaviours 35 .

Moreover, students who were living with their families take more preventive measures compared to those living outside. This is due to enforcement by the family members and the attitude towards COVID-19 was higher among students who were living with their families. Mostly the students travelled only twice during this MCO period due to the strict enforcement of the law, and they were aware of the importance of restriction of movement. The level of knowledge towards COVID-19 among UNIMAS medical students was higher than the preventive practice, and this reveals that knowledge is not necessary to increase the level of preventive practice. Good knowledge needs to be sustained by doing practice. The sustained practise is essential as stated by Erfani et al. (2020) with a higher knowledge score regarding COVID-19 was significantly associated with a higher likelihood of having a positive attitude and good practice at the time of COVID-19 pandemic.

We identified several limitations during the research. First, the results obtained would not be generalised since it was conducted in one faculty in UNIMAS ${ }^{36}$. Secondly, since this is an online survey, the reactions of the students could not be assessed ${ }^{37}$. The results might also be inflated as the participants were medical students with medical knowledge and this can also lead to overreporting as they are equipped with more medical-related resources compared to students from other fields of study ${ }^{38}$. Lastly, participants of this study were required to answer all the questions; hence participants might have filled up without going into depth ${ }^{39}$. 


\section{CONCLUSION}

The current research reports a high level of COVID-19 related knowledge, attitude, and preventive practice against COVID-19 among UNIMAS medical students. The response reflects the efforts made by the Malaysian Government with the help of local authorities to spread broad information to the public about COVID-19. Minority participants in the study showed an unsatisfactory response on the preventive practice towards COVID-19, requiring the need for awareness campaigns and tighter law enforcement. The findings obtained from this study can be used as a bridge for implementing awareness campaigns between university students and the public and aid health authorities in directing their efforts in planning awareness campaigns.

\section{Competing interests}

The authors claim that there is no conflicting interest in this research.

\section{Funding}

Self-funded.

\section{ACKNOWLEDGMENT}

We thankfully acknowledge the students who voluntarily participate in this study. Our sincere gratitude to Professor Chew Keng Sheng, FMHS, for his full support and coordinating the research. We are grateful to Professor Andrew Kiyu, FMHS for his scholarly editing of the final manuscript and comments. We gratefully acknowledge the support from UNIMAS for conducting the research.

\section{REFERENCES}

1. Chen $N$, Zhou $M$, Dong $X$, et al. Epidemiological and clinical characteristics of 99 cases of 2019 novel coronavirus pneumonia in Wuhan, China: a descriptive study. The Lancet. 2020;395(10223):507513. doi:10.1016/S0140-6736(20)30211-7

2. Zhong B-L, Luo W, Li H-M, et al. Knowledge, attitudes, and practices towards COVID-19 among Chinese residents during the rapid rise period of the COVID-19 outbreak: a quick online cross-sectional survey. Int $J$ Biol Sci. 2020;16(10):1745-1752. doi:10.7150/ijbs. 45221

3. WHO. WHO Director-General's opening remarks at the media briefing on COVID-19. Published 2020. Accessed April 18, 2020. https://www.who.int/dg/speeches/detail/ who-director-general-s-opening-remarks-atthe-media-briefing-on-covid-19---11-march2020
4. Huang C, Wang $\mathrm{Y}, \mathrm{Li} \mathrm{X}$, et al. Clinical features of patients infected with 2019 novel coronavirus in Wuhan, China. Lancet. 2020;395(10223):497-506. doi:10.1016/S0140-6736(20)30183-5

5. Guo Y-R, Cao Q-D, Hong Z-S, et al. The origin, transmission and clinical therapies on coronavirus disease 2019 (COVID-19) outbreak - an update on the status. Military Medical Research. 2020;7(1):11. doi:10.1186/s40779-020-00240-0

6. Lana RM, Coelho FC, Gomes MF da C, et al. The novel coronavirus (SARS-CoV-2) emergency and the role of timely and effective national health surveillance. Cadernos de Saúde Pública. 2020;36(3). doi:10.1590/0102-311x00019620

7. Readfearn G. How did coronavirus start and where did it come from? Was it really Wuhan's animal market? The Guardian. https://www.theguardian.com/world/2020 /apr/15/how-did-the-coronavirus-startwhere-did-it-come-from-how-did-it-spreadhumans-was-it-really-bats-pangolinswuhan-animal-market. Published April 15, 2020. Accessed April 18, 2020.

8. CDC. Coronavirus Disease 2019 (COVID-19) Transmission. Centers for Disease Control and Prevention. Published April 13, 2020. Accessed April 15, 2020. https: / /www.cdc.gov/coronavirus/2019ncov/prevent-getting-sick/how-covidspreads.html

9. WHO. Key Messages and Actions for COVID19 Prevention and Control in Schools. Published online 2020. https://www. who.int/docs/defaultsource/coronaviruse/key-messages-andactions-for-covid-19-prevention-andcontrol-in-schools-march2020.pdf?sfvrsn=baf81d52_4

10. Prime Minister's Office of Malaysia. Restriction of Movement Order, 2020. Prime Minister's Office of Malaysia. Published 2020. Accessed April 15, 2020. https://www.pmo.gov.my/2020/03/move ment-control-order/

11. OECD. Reducing the risk of policy failure: challenges for regulatory compliance. Published online 2020. https: / /www.oecd.org/gov/regulatorypolicy/1910833.pdf

12. OECD. Flattening the COVID-19 peak: Containment and mitigation policies. OECD. Published 2020. Accessed May 14, 2020. 
http: / / www.oecd.org/coronavirus/policyresponses/flattening-the-covid-19-peakcontainment-and-mitigation-policiese96a4226/

13. Alzoubi H, Alnawaiseh N, Lubad MA-, Aqel A, Al-Shagahin H. COVID-19 - Knowledge, Attitude and Practice among Medical and Non-Medical University Students in Jordan. Journal of Pure and Applied Microbiology. 2020;14(1):17-24.

doi:10.22207/JPAM.14.1.04

14. Giao H, Nguyen, Thi N, et al. Knowledge and attitude toward COVID-19 among healthcare workers at District 2 Hospital, Ho Chi Minh City. Asian Pacific Journal of Tropical Medicine. 2020;13:1-7. doi:10.4103/19957645.280396

15. IBM SPSS. IBM SPSS Statistics for Windows. IBM SPSS; 2013.

16. Sawyer SF. Analysis of Variance: The Fundamental Concepts. Journal of Manual \& Manipulative Therapy. 2009;17(2):27E-38E. doi:10.1179/jmt.2009.17.2.27E

17. Shingala MC, Rajyaguru DA. Comparison of Post Hoc Tests for Unequal Variance. 2015;2(5):12.

18. Devlieger I, Mayer A, Rosseel Y. Hypothesis Testing Using Factor Score Regression: A Comparison of Four Methods. Educational and Psychological Measurement. 2016;76(5):741-770.

doi:10.1177/0013164415607618

19. Sharma A. Understanding Mahalanobis Distance And Its Use Cases. Analytics India Magazine. Published July 10, 2018. Accessed June 10, 2019. https: / /www.analyticsindiamag.com/under standing-mahalanobis-distance-and-its-usecases/

20. Gray JB, Woodall WH. The Maximum Size of Standardized and Internally Studentized Residuals in Regression Analysis. The American Statistician. 1994;48(2):111-113. doi: $10.2307 / 2684258$

21. Frost J. How to Interpret Adjusted RSquared and Predicted R-Squared in Regression Analysis. Statistics By Jim. Published April 9, 2017. Accessed February 11, 2020. http://statisticsbyjim.com/regression/inte rpret-adjusted-r-squared-predicted-rsquared-regression/
22. Taghrir MH, Borazjani R, Shiraly R. COVID-19 and Iranian Medical Students; A Survey on Their Related-Knowledge, Preventive Behaviors and Risk Perception. Arch Iran Med. 2020;23(4):249-254. doi:10.34172/aim.2020.06

23. Erfani A, Shahriarirad R, Ranjbar K, Moghadami M. Title: Knowledge, Attitude and Practice toward the Novel Coronavirus (COVID-19) Outbreak: A Population-Based Survey in Iran. Bulletin of the World Health Organization. 2020;(e-Pub):1-23.

24. Xu Z, Shi L, Wang Y, et al. Pathological findings of COVID-19 associated with acute respiratory distress syndrome. Lancet Respir Med. $2020 ; 8(4): 420-422$. doi:10.1016/S2213-2600(20)30076-X

25. WHO. Global Surveillance for human infection with coronavirus disease (COVID19). Published 2020. Accessed May 20, 2020. https: / /www.who.int/publicationsdetail/global-surveillance-for-humaninfection-with-novel-coronavirus-(2019ncov)

26. $\mathrm{MOH}$, Malaysia. Guidelines COVID-19 Management In Malaysia. Ministry of Health (Malaysia); 2020. Accessed May 20, 2020. https://www.moh.gov.my/index.php/page s/view/2019-ncov-wuhan-guidelines

27. Liu L, Liu Y-P, Wang J, An L-W, Jiao J-M. Use of a knowledge-attitude-behaviour education programme for Chinese adults undergoing maintenance haemodialysis: Randomized controlled trial. J Int Med Res. 2016;44(3):557-568. doi:10.1177/0300060515604980

28. Aldinger $\mathrm{C}$, Zhang $\mathrm{X}-\mathrm{W}$, Liu $\mathrm{L}-\mathrm{Q}$, et al. Changes in attitudes, knowledge and behavior associated with implementing a comprehensive school health program in a province of China. Health Educ Res. 2008;23(6):1049-1067.

doi:10.1093/her/cyn022

29. De Pretto L, Acreman S, Ashfold MJ, Mohankumar SK, Campos-Arceiz A. The Link between Knowledge, Attitudes and Practices in Relation to Atmospheric Haze Pollution in Peninsular Malaysia. PLoS One. 2015;10(12).

doi:10.1371/journal.pone.0143655

30. Mohamad EM, Azlan AA, Hamzah MR, Tham JS, Ayub SH. Public knowledge, attitudes and practices towards COVID-19: A crosssectional study in Malaysia. medRxiv. Published online May 5, 
2020:2020.04.29.20085563.

doi:10.1101/2020.04.29.20085563

31. Aomo J, Aloka P, Raburu P, Ogolla P. Relationship between Self-Esteem and Indulgence in Behavior Problems among Secondary School Students in Kenya. Mediterranean Journal of Social Sciences. 2018;9(3):135-142. doi:10.2478/mjss-20180055

32. Bennasar-Veny M, Yañez AM, Pericas J, et al. Cluster Analysis of Health-Related Lifestyles in University Students. International Journal of Environmental Research and Public Health. 2020;17(5):1776. doi:10.3390/ijerph17051776

33. Tirodimos I, Georgouvia I, Savvala T-N, Karanika E, Noukari D. Healthy lifestyle habits among Greek university students: differences by sex and faculty of study. East Mediterr Health J. 2009;15(3):722-728.

34. von Bothmer MIK, Fridlund B. Gender differences in health habits and in motivation for a healthy lifestyle among Swedish university students. Nurs Health Sci. 2005;7(2):107-118. doi:10.1111/j.14422018.2005.00227.x
35. Harris C, Jenkins M, Glaser D. Gender differences in risk assessment: Why do women take fewer risks than men? Judgment and Decision Making. 2006;1:4863.

36. Wright KB. Researching Internet-Based Populations: Advantages and Disadvantages of Online Survey Research, Online Questionnaire Authoring Software Packages, and Web Survey Services. J Comput Mediat Commun. 2005;10(3). doi:10.1111/j.10836101.2005.tb00259.x

37. Thompson LF, Surface EA, Martin DL, Sanders MG. From Paper to Pixels: Moving Personnel Surveys to the Web. Personnel Psychology. 2003;56(1):197-227. doi:10.1111/j.1744-6570.2003.tb00149.x

38. Althubaiti A. Information bias in health research: definition, pitfalls, and adjustment methods. J Multidiscip Healthc. 2016;9:211-217. doi:10.2147/JMDH.S104807

39. Nederhof AJ. Methods of coping with social desirability bias: A review. European Journal of Social Psychology. $1985 ; 15(3): 263-280$. doi:10.1002/ejsp.2420150303 